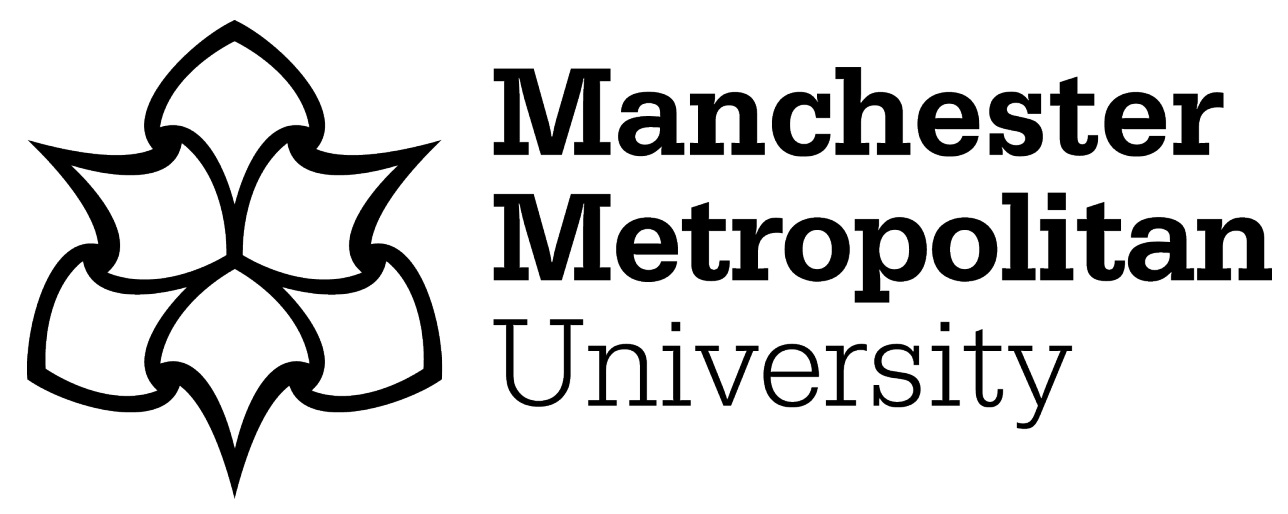

Riedel, Gernot, Grant, Robyn, Sullivan, Matthew and Spink, Andrew (2020) Preface: Special issue on Measuring Behaviour 2018. Journal of Neuroscience Methods, 337. p. 108681. ISSN 0165-0270

Downloaded from: https://e-space.mmu.ac.uk/625839/

Version: Accepted Version

Publisher: Elsevier

DOI: https://doi.org/10.1016/j.jneumeth.2020.108681

Please cite the published version 


\title{
Preface: Special Issue on Measuring Behaviour 2018
}

\author{
Gernot Riedel ${ }^{1}$, Robyn Grant ${ }^{2}$, Matthew Sullivan ${ }^{2}$, Andrew Spink $^{3}$
}

1. University of Aberdeen, UK

2. Manchester Metropolitan University, UK

3. Noldus IT, Netherlands

On the $6-8^{\text {th }}$ of June 2018, we convened the eleventh Measuring Behavior conference at Manchester Metropolitan University. Main local organisers were Robyn Grant and Matthew Sullivan, and together with the Noldus team brought excellent science, good humour and an international audience to central England.

In this special issue, we have assembled a small selection of key papers reflecting a cross section of what was presented. These include presentations and posters alike and are relevant for the audience of the Journal of Neuroscience Methods.

A novelty to our otherwise traditional layout was a workshop on the utility of core facilities, their outlines for different users, their approaches for setting up and their importance for reproducibility and training of personnel. These different approaches are summarised by Likowski et al. The paper describes both advantages of use of and collaboration with core facilities from the perspective of the researcher, but also from the managerial point of view how to run it. An important and scientifically highly relevant issue concerns the increased sophistication of methods. This is addressed together with the quest for standardisation and the flexibility to cater for different species.

Two papers are relevant for movement disorders. In their contribution on hand movement research, Matic \& Gomez-Marin describe a new app for android tablets that enables hand movement recording outside the laboratory at a quality as good as within laboratory solutions. They introduce the app and give example protocols and reveal its flexibility, affordability and high resolution. In the second paper, Bek and co-workers use eye-tracking to record emotions in Parkinson patients. The group for the first time directly compared static and dynamic facial expression and deduced the emotional responses on patients through eye movements. Subtle differences occurred, especially when dynamic stimuli are presented.

In terms of animal behaviour, several papers deal with whisper and movement and locomotor activity in rodents. Gillespie and co-workers introduce the new system LocoWhisk. It offers standardised software and hardware solutions for the simultaneous recording of whisker movements and gait analysis. Animals are placed in the LocoWhisk arena and recorded by high-speed camera and the detector algorithms (ARTV2) produce data like what has been published by established tools. Recommendations for the conduct and analysis of whisker movement and gait analysis are presented by Simanaviciute and colleagues. By standardisation of protocols and comparison across multiple mouse models of diseases and background strains, the authors recommend that deficits in whisker movement and locomotion are best recorded synchronously and analysed together in structureless open field. For the detection of sensory impairments, more complex environments containing obstacles are better suited. A data mining procedure is introduced by Timotius and colleagues have used the CatWalk for investigations into Parkinsonian 
mice. By employing a complete data mining protocol, in which all parameters available from the video recording are summarised and heat mapped, they produce a new way of data analysis and report on previously not considered outputs of relevance. This is a significant improvement and avoids data bias compared to presenting parameters preselected a-priori.

Another advanced video-based analysis approach was presented by Haalck et al. They used hand-held (or drone operated) video cameras to record animal behaviour and applied a 'video-key frame selection scheme combined with geometrically constrained image stitching algorithms' to extract meaningful animal trajectories in a two-dimensional panorama reflecting the environment. Data presented are accurate reflections of the animals moving in space and methods for enhancement of the current methodology for upgrading to real time imaging are explored. A different approach is applied by Peleh and associates for the study of social behaviour in groups of animals. Subjects were equipped with radio-frequency identification chips (RFID) and in combination with vide tracking, the software tool (Socialscan) extracts pre-defined interaction events between mice. The authors report details of the tool and its validation by observing groups of C57BL/6J mice over several days in ethologically relevant contexts. Finally, Thomson et al. present another video-based analysis tool, which they term the Chromatic Fish Analyser. Combined recording of hue (horizontal camera) and spatial location (vertical camera) of the fin-clipped fish enabled separation of multiple individuals (here up to 6) by spatial chromatic analysis. Tank applied lidocaine lead to significant alterations in fish behaviour which was traced accurately with this system.

This was the second time Measuring Behaviour was held outside Netherlands, and it was a big success. As we write this Editorial, preparations are in full swing for the next meeting in a couple of months. We hope you will be joining us at Measuring Behavior in Krakow, Poland, from 27-29 May 2020. 


\section{References:}

Bains, R.S., Sillito, R.R., Armstrong, J.D., Cater, H.L., Banks, G., Nolan, P.M. 2018. Assessing mouse behaviour throughout the light/dark cycle using automated in-cage analysis tools. J. Neurosci. Methods,

Bespalov, A., Steckler, T. 2018. Lacking quality in research: Is behavioral neuroscience affected more than other areas of biomedical science? J. Neurosci. Methods,

Brown, R. 2018. The Importance of Behavioural Bioassays in Neuroscience. J. Neurosci. Methods,

French, F., Mancini, C., Sharp, H. 2018. High tech cognitive and acoustic enrichment for captive elephants. J. Neurosci. Methods,

Garland, H., Wood, N.I., Skillings, E.A., Detloff, P.J., Morton, A. J., Grant, R.A. 2018. Characterisation of progressive motor deficits in whisker movements in R6/2, Q175 and Hdh knock-in mouse models of Huntington's disease. J. Neurosci. Methods,

Giovannucci, A., Pnevmatikakis, E.A., Deverett, B., Pereira, T., Fondriest, J., Brady, M.J., Wang, S.S-H., Abbas, W., Par'es, P., Masip, D. 2018. Automated gesture tracking in headfixed mice. J. Neurosci. Methods

Hawkins, P., Gollege, H.D.R. 2018. The 9 to 5 Rodent - Time for Change? Scientific and welfare implications of circadian and light effects on laboratory mice and rats. J. Neurosci. Methods

Hewitt, B.M., Yap, M.H., Hodson-Tole, E.F., Kennerley, A.J., Sharp, P.S., Grant, R.A. 2018. A novel automated rodent tracker (ART), demonstrated in a mouse

model of amyotrophic lateral sclerosis. J. Neurosci. Methods

König, M., Thinnes, A., Klein, J. 2018. Microdialysis and its significance for measuring behaviour. J. Neurosci. Methods

Kyriakou E.I., Nguyen, H.P., Homberg, J.R., Van der Harst, J.E. 2018. Home-cage anxiety levels in a transgenic rat model for

Spinocerebellar Ataxia type 17 measured by an approach-avoidance task:

the light spot test. J. Neurosci. Methods

Lorbach, M., Kyriakou, E.I., Poppe, R., van Dam, E.A., Noldus, L.P.J.J., Veltkamp, R.C. 2018. Learning to Recognize Rat Social Behavior: Novel Dataset and Cross-Dataset Application. J. Neurosci. Methods,

Möller, K.A., Svärd, H., Suominen, A., Immonen, J., Holappa, J., Stenfors, C. 2018. Gait analysis and weight bearing in pre-clinical joint pain research. J. Neurosci. Methods,

O'Connor, J.J., O'Boyle, K.M., Lowry, J.P. 2018. Effects of a combination of 3,4methylenedioxymethamphetamine and caffeine on real time stimulated dopamine release in the rat striatum. J. Neurosci. Methods,

Peirson, S.N., Brown, L.A., Pothecary, C.A., Benson, L.A., Fisk, A.S. 2018. Light and the laboratory mouse. J. Neurosci. Methods 
Roemers, P., Mazzola, P.N., De Deyn, P.P., BossersW.J., 3, van Heuvelen, M.J.G., van der Zee, E.A. 2018. * $^{*}$ Burrowing as a Novel Voluntary Strength Training Method in Mice: A Qualitative Comparison Of Various Voluntary Strength or Resistance Exercise Methods. J. Neurosci. Methods

Strachan, L., Spruijt, B., Riedel, G. 2018. Between and within laboratory reliability of mouse behaviour recorded in home-cage and open-field. J. Neurosci. Methods

Ungar, E.D., Nevo, Y., Baram, H., Arieli, A. 2018. Validation of the IceTag leg sensor and its utility in the inference of beef cattle behaviour on rangeland. J. Neurosci. Methods

Weiss, C., Procissi, D., Power, J.M., Disterhoft, J.F. 2018. The Rabbit as a Behavioral Model System for Magnetic Resonance Imaging. J. Neurosci. Methods

Werner, J., Leso, L., Umstatter, C., Niederhauser, J., Kennedy, E., Geoghegan, A., Shalloo, L., Schick, M., O'Brien, B. 2018. Evaluation of the RumiWatchSystem for measuring grazing behaviour of cow. J. Neurosci. Methods,

Witham, CL. 2018. Automated Face Recognition of Rhesus Macaques. J. Neurosci. Methods,

Zimprich, A., Östereicher, M.A., Becker, L., Dirscherl, P., Ernst, L., Fuchs, H., Gailus-Durner, V., Garrett, L., Giesert, F., Glasl, L., Hummel, A., Rozman, J., de Angelis, M.H., VogtWeisenhorn, D., Wurst, W., Hölter, S.M. 2018. Analysis of Locomotor Behavior in the German Mouse Clinic. J. Neurosci. Methods,

Zylstra, B., Netscher, G., Jacquemot, J., Schaffer, M., Fella, A., Shen, G., Bowhay, A.D., Braley, T.L., Possin, K.L., Miller, B.L., Bayen, A.M., Schenk, A.K., Bonasera, S.J. 2018. Extended, continuous measures of functional status in community dwelling persons with Alzheimer's and related dementia: infrastructure, performance, trade-offs, preliminary data, and promise. J. Neurosci. Methods, 